\title{
Giving Voice beyond Her Vote: How Women Used Charitable Giving to Create Social Change after the 2016 U.S. Presidential Election
}

\begin{abstract}
${ }^{1}$ Lilly Family School of Philanthropy, Indiana University-Purdue University Indianapolis, 301 University Blvd., Suite 300, Indianapolis, IN 46202-5143, USA, E-mail: dmesch@iupui.edu, uosili@iupui.edu, jjbergdo@iupui.edu, tbskidmo@indiana.edu, jacacker@iupui.edu,hanxia@iupui.edu
\end{abstract}

\begin{abstract}
:
This study fills a gap in research on the philanthropic outcomes of political events. More specifically, it provides empirical evidence to supplement anecdotal reports that nonprofit organizations experienced a substantial increase in donations following the 2016 U.S. presidential election. Based on daily transaction data from an online giving platform, the study uses random-effect panel Ordinary Least Squares models to examine whether and how charitable giving patterns changed after Election Day 2016. Overall, our analyses show no evidence of increased giving due to the election; however, gender differences are apparent. Women donated in greater amounts than men following Election Day, and they appear to have targeted relevant progressive charities with their giving.
\end{abstract}

Keywords: charitable giving, elections, gender, philanthropy, women

DOI: $10.1515 / \mathrm{npf}-2019-0054$

\section{Introduction}

Political elections provide an opportunity for Americans to shape public policy and make their voices heard. The 2016 U.S. presidential election was unique - and divisive - in many ways. With a major political party putting forth a female candidate for the first time and contentious issues that affect women being widely discussed, gender played a key role in the campaign. Exit polls showed the widest gender gap in voting in recent decades: men favored Republican Donald Trump by a 12 \% point margin, while women preferred Democrat Hillary Clinton by the same margin. Following the election, social movements such as the Women's March sprang up, addressing gender equality and reproductive rights, among other topics perceived as being under threat by the incoming administration.

This paper describes changes in charitable giving around the 2016 U.S. presidential election. The study uses daily transaction data from an online donation platform during the time period immediately leading up to and following the election. Importantly, we also examine gender differences in giving around the election, since research demonstrates that women and men exhibit varying patterns in their philanthropy and are motivated to donate by different factors (Mesch et al. 2011). The study finds that, overall, charitable giving was lower than expected immediately following the 2016 presidential election, especially among men. However, following the election, donations to progressive-leaning nonprofits directly connected to issues raised during the 2016 election campaign significantly increased. This increase in charitable giving to relevant progressive nonprofits was primarily driven by women donors. The results provide helpful insight for scholars and fundraising practitioners, regarding how donors - particularly women - may express their values through giving during political events.

This study contributes to a growing body of literature on the economic and social outcomes of political events (Dolan 2006; Białkowski, Gottschalk, and Wisniewski 2008). It also provides empirical evidence to supplement anecdotal reports that nonprofit organizations experienced a substantial increase in donations following the 2016 U.S. presidential election (Financial Times 2018). The popular media referred to this phenomenon as "rage giving" - the concept of donors giving to charity in response to the outcome of the election, often to causes that had been debated during the campaign, including minority rights, immigrant rights, and climate 
change (Paynter 2017; Segedin 2018). While this purported increase in philanthropic contributions around the election was widely covered in media stories, no methodologically rigorous studies have been conducted to date to confirm or quantify this trend, particularly with regard to which demographic groups were most likely to give.

\section{Literature Review}

There is a rich history of giving time and financial resources in the United States. In 2018, \$427.7 billion was donated to U.S. charities. More than three-quarters of total giving came from individuals, ${ }^{1}$ and inflation-adjusted donations by individuals have nearly doubled in the last 25 years (Giving USA Foundation 2019). Long-running studies show that a majority of American households give to charity - $56 \%$ in 2014, with the average donor household contributing around \$2,500 (Indiana University Lilly Family School of Philanthropy 2017). A large body of literature explains why people give to charity. For example, studies in the field of psychology suggest that individuals may donate out of pure altruism, or due to more selfish motives such as prestige, social pressure, or simply because giving feels good (Becker 1974; Andreoni 1989; Hernandez-Murillo and Roisman 2005). Economic conditions may also shape charitable giving. The Standard \& Poors 500 Index (S\&P 500), personal consumption, and gross domestic product have been shown to influence giving, with one study demonstrating that S\&P 500 performance accounts for almost $40 \%$ of annual variation in charitable contributions (List 2011; List and Peysakhovich 2011).

A much smaller proportion of Americans donate time and resources to political candidates. However, the share of the U.S. population that gives politically is growing - from $6 \%$ to $12 \%$ of adults in the last 25 years (Hughes 2017). During the 2016 presidential election campaign, the two main candidates generated a combined \$2.4 billion (Center for Responsive Politics 2017a). Individual donors contributed a large portion of this amount, comprising $71 \%$ of Hillary Clinton's and $40 \%$ of Donald Trump's fundraising totals (Center for Responsive Politics 2017b, 2017c). ${ }^{2}$ Extensive research on why Americans give to political candidates or campaigns reveals two primary motivations. First, people may give to politics as a way of participating in the political process (Gordon, Hafer, and Landa 2007; Ansolabehere, de Figueiredo, and Snyder 2003; Verba, Schlozman, and Brady 1995). Second, they may give to affect policy outcomes (Gordon, Hafer, and Landa 2007; Aranson and Hinich 1979; Grossman and Helpman 2001; Hall and Wayman 1990; Langbein 1986; Snyder 1990).

While scholarly research linking political giving with charitable giving is sparse, studies suggest that charitable giving and political giving are complementary (Yörük 2015). Descriptive research has analyzed amounts donated for charitable and political purposes compared with demographic characteristics. One study found that, across general and high-net-worth-donor populations, households are more likely to give to both charitable and political organizations as the age of the head of household increases, the education level of the head of household increases, and as household income rises. ${ }^{3}$ Additionally, the likelihood of giving to charitable organizations among these populations increases as the number of children under the age of 18 in a household rises (Giving USA Foundation 2012). Other research shows that donors who gave to federal political campaigns in 2012 (a presidential election year) contributed approximately $1 \%$ more to the charitable organizations studied in 2012 than they did in 2011. Donors who did not contribute to such campaigns reduced their charitable giving by $2 \%$ from 2011 to 2012. These findings were consistent across all demographic traits measured, including head of household gender (O'Shaughnessy 2016).

Beyond political giving, academic research examining the effects of one's politics on charitable giving is even more limited. One of the few studies to directly address this topic found that, among individuals with high moral identity internalization (i. e. the degree to which moral traits are central to a person's self-concept), donations increase when there is alignment between one's political identity and a charity's moral foundations (Winterich, Zhang, and Mittal 2012). Another study found that lack of trust in government is an important predictor of certain types of charitable giving and all types of volunteering (Brooks and Lewis 2001). While these studies illuminate personal characteristics and viewpoints that may have motivated Americans to donate to charity around a presidential election, the authors are not aware of any research on the impact of political events themselves on charitable giving, or how charitable giving in response to political events varies by gender. This study aims to fill this gap in the literature.

\section{Methodology and Empirical Framework}

This study seeks to answer the following research questions: 
1. Did charitable giving patterns change after Election Day (November 8, 2016)?

2. Did changes in post-Election Day charitable giving vary by gender?

3. Did changes in post-Election Day giving vary by type of charitable organization?

To test whether the election itself affected charitable giving, random-effect panel Ordinary Least Squares models were used, which controlled for date information. We estimated these models using both 2015 and 2016 donation information. We were particularly interested in 2015 data as it allows us to compare giving patterns in the context of a non-election year.

The baseline model can be expressed as:

$$
y_{i t}=\beta_{0}+\beta_{1} \text { PostElectionWeek }_{i}+\boldsymbol{x}_{\boldsymbol{i t}} \boldsymbol{\gamma}+\theta t+\boldsymbol{c}_{\boldsymbol{i}}+e_{i}
$$

Where $y_{i t}$ is the outcome variable of interest, such as the natural log of average daily donation amounts for organization $i$ at time $t ; \boldsymbol{x}_{\boldsymbol{i t}}$ are controls for organizational characteristics, such as type, revenue, and year founded; $t$ is the time effect; $c_{i}$ is the unobserved component, and $e_{i}$ are the idiosyncratic errors. It is assumed that $E\left(c_{i} \mid x_{i t}\right.$, PostElectionWeek $\left.{ }_{i}\right)=0$.Standard errors are clustered at the organizational level in all regressions. ${ }^{4}$ The primary analysis was performed using a Heckman maximum likelihood on a balanced panel, with the exclusionary criterion being an organization receiving $\$ 0$ on a given day.

The study uses data from Charity Navigator, a 501(c)(3) organization that evaluates U.S. nonprofits. Visitors to the organization's website can find basic information on all U.S. charities, as well as evaluations of more than 9,000 nonprofits. They can also donate to these charities via the "Giving Basket" feature. Charity Navigator provided Giving Basket daily transaction data for this research, and merged the data with demographic information about donors and organizational data on the nonprofits. The data set contains information on the gifts themselves (e. g. amount, date, and time), donors (e. g. gender, income, and location), and organizations receiving the donations (e. g. EIN and nonprofit subsector).

The full data set spanned the time period from October 29, 2015 to January 1, 2018; regression analyses that underlie the study's findings used the full data set. Robustness checks were performed on several windows of time around Election Day to ensure the results were consistent. To focus on the impact of the 2016 presidential election, the data reflected in the main results described below come from November 1, 2016 to November 15 , 2016 - one week before and after Election Day (November 8, 2016).

The analyses for this study used a subset of data from the top 131 charities, defined as any organization in the top 100 by either number or amount of donations. Robustness checks were also run with a larger set of charitable organizations (the 436 organizations in the data that received at least 50 total donations) and the results were similar (see Robustness Checks section below for details). Charities in this subset were manually coded for political leaning. All organizations in the data set are 501(c)(3) public charities and are therefore limited in the advocacy or overt political actions they can take; the following categories are based on perceived political leaning only.

Categories included:

- Control: No identifiable political leaning (e.g. Alzheimer's Association, Food for the Poor, American Red Cross)

- Conservative: A perceived conservative political leaning (e. g. Wounded Warriors Project, Operation Homefront)

- General progressive: A perceived progressive political leaning (e. g. the Greenpeace Fund, World Wildlife Fund)

- Relevant progressive: A perceived progressive political leaning that also has a direct connection to the 2016 election campaign (e. g. Planned Parenthood Federation, American Civil Liberties Union, National Immigration Law Center, Southern Poverty Law Center)

Note that while the "relevant progressive" category is of particular interest to this study, no "relevant conservative" category was used. This is for two key reasons. First, since the 2016 presidential election results favored conservative causes, "rage giving" in response to those results tended to come from individual donations to more progressive causes rather than conservative causes. Second, throughout the coding process, researchers evaluated whether organizations could be categorized as relevant conservative charities, but none fit this classification. 


\section{Data}

Data for the top 131 charitable organizations were collapsed in two different ways. First, all donations by organization by day were collapsed, so that each organization had one observation per day. The dependent variable used in the analyses shown is the log of total donations received by each organization on that day. Second, all donations by gender by organization by day were collapsed. In other words, donations from men and women donors were collapsed separately, so that each organization had two observations per day. This allowed for closer analysis by gender. Table 1 provides summary statistics of the data.

Table 1: Summary statistics for top charitable organizations.

\begin{tabular}{lll}
\hline & Mean & Standard deviation \\
\hline Average Daily Donation Amount & $\$ 118.57$ & $\$ 1,012.61$ \\
$\%$ Female Donors & $51.46 \%$ & 0.43 \\
Average Daily Number of Gifts & 0.90 & 5.10 \\
& & \\
Political category & & 0.48 \\
$\%$ Control & $64.6 \%$ & 0.39 \\
$\%$ General Progressive & $19.23 \%$ & 0.29 \\
$\%$ Conservative & $9.28 \%$ & 0.28 \\
$\%$ Relevant Progressive & $8.46 \%$ & \\
Type of organizations & & \\
Arts & $1.67 \%$ & \\
Education & $1.67 \%$ & \\
Environments/Animals & $20.83 \%$ & \\
Health & $14.17 \%$ & \\
Human Services & $15.83 \%$ & \\
Other/Unknown & $45.83 \%$ & \\
Sample size & & \\
\hline
\end{tabular}

\section{Results}

We first examine whether charitable giving patterns changed after Election Day 2016. Descriptive statistics indicate that, while total dollars given to charity increased around Election Day, this can be attributed to the regular rise in giving toward the end of the calendar year rather than due to the 2016 election.

We also find no evidence of "rage giving," or giving above and beyond what would be expected in a nonelection year. In fact, giving to charity slowed in the days following the 2016 U.S. presidential election, compared to the level that would normally be expected based on previous non-election years (see Appendix Figure 4).

These descriptive results are supported by regression analysis. Table 2 displays the baseline results. 


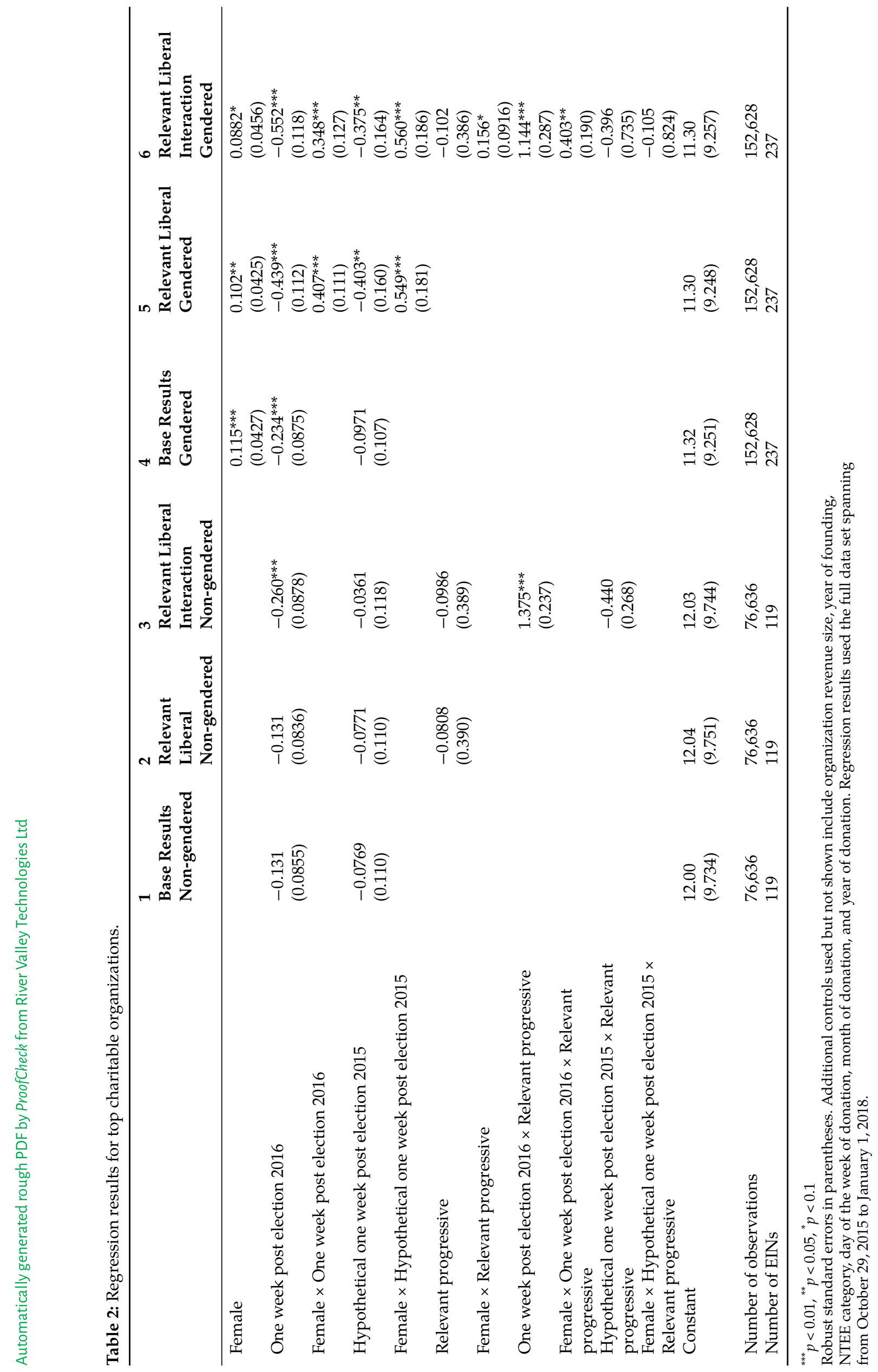


We turn next to whether changes in post-Election Day charitable giving varied by gender. Here, exploring giving by women and men reveals a clear gender difference in both the descriptive statistics and the regression results. In comparison to men donors, women donors gave higher dollar amounts to charity in the week following the election. While the trend in overall giving by men and women looks similar leading up to Election Day 2016, women's giving increased much more than men's giving post-election (see Figure 1). This trend, however, was not discernably different than the one seen following a hypothetical election day in 2015.

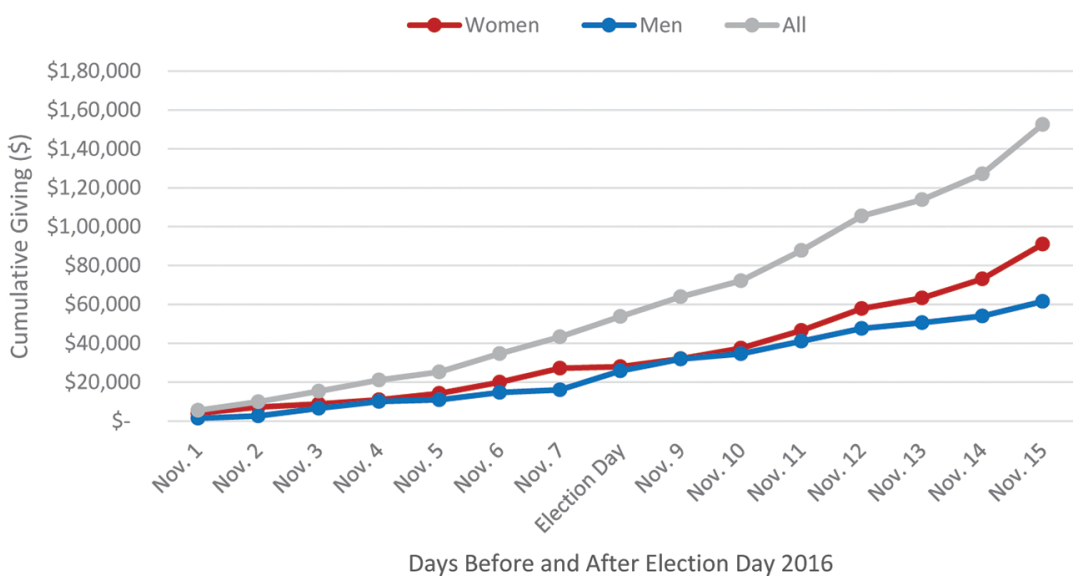

Figure 1: Cumulative giving one week before and after Election Day 2016 by donor gender.

Next, we explore whether changes in post-Election Day giving vary by type of charitable organization. An initial analysis of key characteristics of 501(c)(3) organizations receiving funding around the 2016 U.S. presidential election showed no significant effect on post-election donations. These characteristics, such as nonprofit subsector or size, did not impact whether a charity saw an increase in donations after Election Day.

However, when organizations were classified according to perceived political leaning or particular relevance to the 2016 election cycle, significant differences appeared (see Figure 2). While the trend in cumulative giving to all other organizations (i. e. every top nonprofit not classified as relevant progressive) appears relatively stable throughout the time period before and after Election Day, overall giving to relevant progressive nonprofits experienced a significant upward shift the week after Election Day.

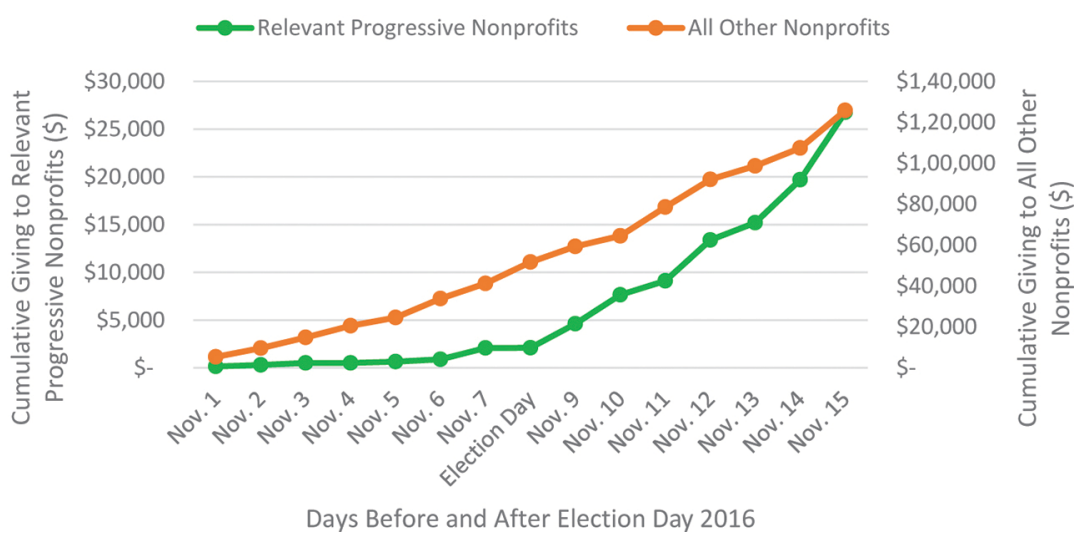

Figure 2: Cumulative giving one week before and after Election Day 2016 by relevant progressive and all other nonprofits. Dual Y-axes are used to emphasize the difference in the cumulative giving trend between relevant progressive organizations and all other organizations, rather than the overall dollar amounts. Because relevant progressive organizations are a relatively small share of all organizations, they receive lower total charitable donations.

Table 2 presents results for donation amounts to organizations in the data set during the week after the 2016 U.S. presidential election. The dependent variable in all columns is the natural log of donation amounts. Column 1 demonstrates that donation amounts did not change during the first week after the 2016 presidential election, holding other factors constant. Column 2 shows similar results. However, column 3 reveals that relevant progressive organizations saw a significant increase in the amount of their donations during the week following the 2016 election compared to other organizations $(p<0.01)$.

We find that women's charitable giving increased more than men's post-election, though this may have been a seasonal effect. We also find that giving to relevant progressive charitable organizations increased more than giving to other charities post-election. Regression analysis supports this finding: In the columns with 
gender, we find that, conditional on giving, donation amounts dropped substantially during the week after the election, with a decline across models. The results demonstrate that women gave more across all time periods. The female and post-election week interaction terms indicate that women gave more than men during the week following the election, though this was also true in the week following a hypothetical 2015 election.

The results indicate that women are driving the trend of increased giving to relevant progressive charities post-election. While men and women both significantly increased their giving to progressive organizations with particular relevance to the 2016 election cycle, women's giving increased significantly more. Additionally, although women may have donated in greater amounts than men overall following the election, they certainly targeted relevant progressive charities with their contributions.

Figure 3 illustrates this gender difference beginning around Election Day 2016. During the week leading up to the election, cumulative giving by men and women to relevant progressive nonprofits appears relatively comparable. In the week following the election, cumulative giving by women increases at a rate far surpassing that of men, supporting the findings of the regression models mentioned above.

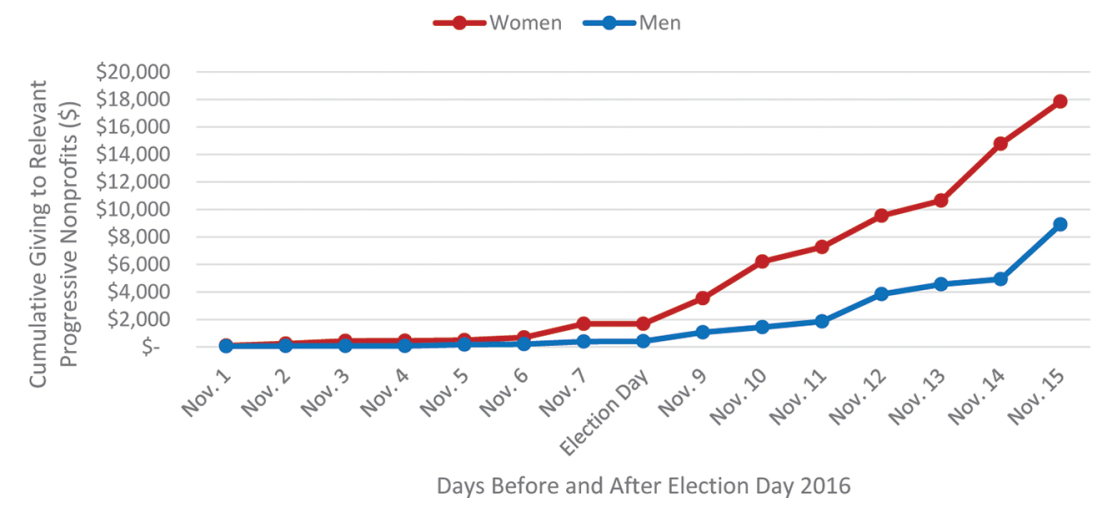

Figure 3: Cumulative giving to relevant progressive organizations one week before and after Election Day 2016 by donor gender.

\section{Robustness Checks}

To test the robustness of the results, we conducted additional analyses with various functional forms and specifications.

First, we expanded the sample from 131 to 436 organizations and repeated the same analyses. The analyses continued to show the broad finding that women gave more than men in the week following the election (the result is actually clearer and stronger here than in the baseline). We no longer see the same significance with the relevant liberal variables; this could be due to increased donations only affecting the largest organizations (since the sample was selected based on prevalence within the dataset by donation number), or it could be due to reduced coding accuracy for the expanded list of organizations.

Second, we expanded the time frame to understand how long the post-election effect lasts. The results seem to indicate that women's increased giving stays relatively strong even eight weeks post-election. However, women's giving to relevant progressive organizations post-election loses significance after one week. Essentially, women continue to give more than men overall up to eight weeks post-election, but their specific support of relevant progressive organizations only lasts for the first week. Overall support for relevant progressive organizations continues after the first week, but goes from being gendered to non-gendered at this point.

Other robustness checks involved:

- Closely examining each day during the week before and after the 2016 U.S. presidential election. On most days prior to the election, women gave less than men, and relevant progressive organizations received less than non-relevant progressive organizations. These results reversed following the election: On most days during the week after the election, women gave more than men, and relevant progressive organizations received more than non-relevant progressive organizations.

- Controlling for time trends specific to organization type, the results are very similar to those in Table 2. The results for the median regression show that the median donation amount was $\$ 70$ less during the week following the election. However, the median donation amount to relevant progressive organizations was $\$ 50$ more than all other types of organizations.

All results for these robustness checks are available upon request. 


\section{Discussion and Conclusion}

This study contributes to scholarly research on the economic and social outcomes of political events in a unique way by analyzing changes in charitable giving around the 2016 U.S. presidential election. In particular, the paper provides new insight on gender differences in individuals' philanthropic responses to political events. Examining variation in charitable giving by donor gender leads to a more complete understanding of philanthropic phenomena since research has shown that women and men demonstrate different patterns in their giving.

Overall, our analyses show no evidence of increased charitable giving due to the 2016 U.S. presidential election; if anything, the election may have depressed giving. However, gender differences are apparent. Women donated in greater amounts than men following Election Day, and they appear to have targeted relevant progressive charities with their giving. Although the analyses for this study cannot determine the exact reason for these difference, previous research points to some possible explanations.

While this study is unique in its analysis of the impact of political events themselves on charitable giving, the results are consistent with existing research on the effects of individuals' personal politics on their philanthropy. Winterich, Zhang, and Mittal found that, among individuals with high moral identity internalization (i. e. the degree to which moral traits are central to a person's self-concept), donations increase when there is alignment between one's political identity and a charity's moral foundations (2012). Research has shown that women have more strongly internalized moral identities than men (Kennedy, Kray, and Ku 2017), which could increase the likelihood they ensure the charities to which they donate are aligned with their political persuasions, especially following a major event like the 2016 U.S. presidential election.

This study also aligns with the finding of Brooks and Lewis that lack of trust in government is an important predictor of certain types of charitable giving and all types of volunteering (2001). The Pew Research Center has demonstrated a growing gender gap in Americans' level of optimism about the country's future (2017). While men's confidence in the future of the U.S. increased by 6 \% points between October 2015 and April 2017, women's confidence in the future of the country declined by $14 \%$ points during the same period. This trend, combined with the wide gender gap in voting during the election, could have led women to be more distrusting of the new administration after the 2016 presidential election, increasing their likelihood to give.

It is important to note that the data set used for this study is limited to donations given via Charity Navigator's website, which represent a small portion of U.S. charitable donations and is not necessarily representative of all donations. Since the data set is comprised of online donations, the findings may not be generalizable for all charitable giving. Individuals who give through Charity Navigator likely differ from the general donor population along characteristics like their decision-making processes. Since a major function of Charity Navigator is to evaluate charitable organizations, individuals donating through this platform may gather more information about charities and be more discerning about the organizations to which they give than other donors. Additionally, this study is limited in that it only examines the impact of one presidential election year - 2016 - which was unique in many ways.

To generate greater knowledge about how political events like elections impact charitable giving more broadly, further research should include data from a number of years, as well as election cycles with a variety of outcomes. For example, it is not clear whether progressive nonprofits would have seen the same rise in giving, or if women donors would have increased their giving to a similar extent, if the outcome of the 2016 election had been different. Further research should also include data on donations made through a variety of methods (e. g. phone, text, mail, online) to be more representative of overall charitable giving in the U.S. Additionally, research could examine how a variety of other political or social events might affect charitable giving, such as the 2018 confirmation hearings for Supreme Court Justice Brett Kavanaugh.

\section{Funding}

This research was completed with funding from the Bill and Melinda Gates Foundation, Funder Id: http:/ /dx.doi.org/10.13039/100000865. 


\section{Appendix}

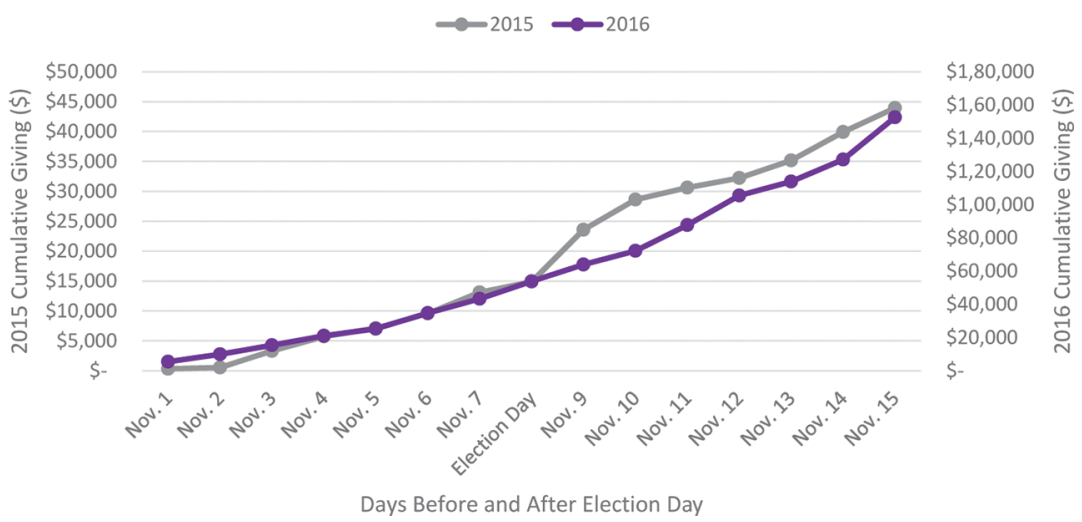

Figure 4: Cumulative giving one week before and after Election Day 2016 and hypothetical Election Day 2015.

Note: Between 2015 and 2016, Charity Navigator experienced significant growth in the amount of donations processed through its website. Dual Y-axes are used to emphasize the difference in cumulative giving trends between these years, rather than overall dollar amounts.

\section{Notes}

1 This figure includes bequest giving.

2 According to the Center for Responsive Politics, women gave more than men to political candidates in 2016 than they did in past presidential elections. The organization found that women donors giving $\$ 200$ or more made $\$ 1.32$ billion in campaign contributions in 2016 , compared to $\$ 0.81$ million in contributions in 2012. However, men regularly donate more to political campaigns than women. The Center for Responsive Politics found that men consistently give more than two-thirds of all itemized donations over $\$ 200$ to campaigns in terms of contribution amounts (Center for Responsive Politics 2017d).

3 This study did not measure head of household gender.

4 Since our data has relatively long panels ( $t$ is over 600), we also used other estimation methods that allow for more flexible correlation of errors. In general, models that allow for autoregressive errors produce bigger standard errors, but our results are still significant.

\section{References}

Andreoni, J. 1989. “Giving with Impure Altruism: Applications to Charity and Ricardian Equivalence.” Journal of Political Economy 97 (6): 144758.

Ansolabehere, S., J. M. de Figueiredo, and J. M. Snyder. 2003. "Why is There so Little Money in U.S." Politics? Journal of Economic Perspectives 17 (1): 105-30.

Aranson, P. H., and M. J. Hinich. 1979. “Some Aspects of the Political Economy of Election Campaign Contribution Laws." Public Choice 34 (34): 435-61.

Becker, G. S. 1974. “A Theory of Social Interactions." Journal of Political Economy 82 (6): 1063-93.

Białkowski, J., K. Cottschalk, and T. P. Wisniewski. 2008. “Stock Market Volatility around National Elections." Journal of Banking $\&$ Finance 32 (9): 1941-53.

Brooks, A. C., and G. B. Lewis. 2001. “Giving, Volunteering, and Mistrusting Government." Journal of Policy Analysis and Management 20 (4): 765-70.

Center for Responsive Politics. 2017a. 2016 Presidential Race. OpenSecrets.org. Retrieved from https://www.opensecrets.org/pres16

Center for Responsive Politics. 2017b. Hillary Clinton (D). OpenSecrets.org. Retrieved from https://www.opensecrets.org/pres16/candidate?id=No0000019

Center for Responsive Politics. 2017c. Donald Trump (R). OpenSecrets.org. Retrieved from https://www.opensecrets.org/pres16/candidate?id=N00023864

Center for Responsive Politics. 2017d. Donors Demographics. OpenSecrets.org. Retrieved from https://www.opensecrets.org/overview/donordemographics.php?cycle=2016\&filter=C

Dolan, K. 2006. “Symbolic Mobilization? the Impact of Candidate Sex in American Elections.” American Politics Research 34 (6): $687-704$.

Financial Times. 2018. Donations to Charitable Croups Surge after Trump Victory. Retrieved from https://www.ft.com/content/c7cd138a-a84611e6-8898-79a99e2a4de6

Giving USA Foundation. 2012. Giving USA Spotlight: Characteristics of American Households that Give to Charity and Political Organizations. Chicago: Civing USA Foundation.

Giving USA Foundation. 2019. Civing USA: The Annual Report on Philanthropy for the Year 2018. Chicago: Giving USA Foundation. 
Gordon, S. C., C. Hafer, and D. Landa. 2007. “Consumption or Investment? On Motivations for Political Civing.” Journal of Politics 69 (4): $1057-$ 72.

Grossman, G., and E. Helpman. 2001. Special Interest Politics. Cambridge, MA: MIT Press.

Hall, R. L., and F. W. Wayman. 1990. "Buying Time: Moneyed Interests and the Mobilization of Bias in Congressional Committees." American Political Science Review 84 (3): 797-820.

Hernandez-Murillo, R., and D. Roisman 2005. The Economics of Charitable Giving: What Gives? The Regional Economist, Oct., 12-13

Hughes, A. 2017. 5 Facts about U.S. Political Donations. Pew Research Center, Fact Tank: News in the Numbers. Retrieved from http://www.pewresearch.org/fact-tank/2017/05/17/5-facts-about-u-s-political-donations/

Indiana University Lilly Family School of Philanthropy. 2017. Overview of Overall Giving, Based on Data Collected in 2015 about Giving in 2014. GenerosityForLife. Retrieved from http://generosityforlife.org/wp-content/uploads/2017/10/Overall-Giving-10.5.17-jb-C]C.pdf

Kennedy, J. A., L. J. Kray, and G. Ku. 2017. "A Social-Cognitive Approach to Understanding Cender Differences in Negotiator Ethics: The Role of Moral Identity." Organizational Behavior and Human Decision Processes 138 (1): 28-44.

Langbein, L. 1986. “Money and Access: Some Empirical Evidence." Journal of Politics 48 (4): 1052-62.

List, J. A. 2011. "The Market for Charitable Civing." The Journal of Economic Perspectives 25 (2): 157-80.

List, J. A., and Y. Peysakhovich. 2011. “Charitable Donations are More Responsive to Stock Market Booms than Busts.” Economics Letters 110 (2): 166-69.

Mesch, D. J., M. S. Brown, Z. I. Moore, and A. D. Hayat. 2011. “Cender Differences in Charitable Civing." International Journal of Nonprofit and Voluntary Sector Marketing 16 (4): 342-55.

O'Shaughnessy, J. 2016. Giving in an Election Year: How Political Civing Effects Nonprofit Support. Blackbaud Institute. Retrieved from https://institute.blackbaud.com/wp-content/uploads/2016/10/GIEY.pdf

Paynter, B. 2017. Philanthropy in 2017 Saw the Rise of Trump-Powered Civing. Fast Company. Retrieved from https://www.fastcompany.com/40499097/philanthropy-in-2017-saw-the-rise-of-trump-powered-giving

Pew Research Center. 2017. Growing Cender Cap in Optimism about the Country's Future. Retrieved from http://www.peoplepress.org/2017/05/03/public-trust-in-government-remains-near-historic-lows-as-partisan-attitudes-shift/6-18/

Segedin, A. (2018). 'Rage' Civing Fueled Uptick in 2017 Fundraising. The NonProfit Times. Retrieved from http://www.thenonprofittimes.com/news-articles/rage-giving-fueled-uptick-2017-fundraising/

Snyder, J. M. 1990. “Campaign Contributions as Investments: The U.S. House of Representatives, 1980-1986." Journal of Political Economy 98 (6): 1195-227.

Verba, S., K. L. Schlozman, and H. Brady. 1995. Voice and Equality. Cambridge, MA: Harvard University Press.

Winterich, K. P., Y. Zhang, and V. Mittal. 2012. “How Political Identity and Charity Positioning Increase Donations: Insights from Moral Foundations Theory." International Journal of Research in Marketing 29 (4): 346-54.

Yörük, B. K. 2015. “Do Charitable Subsidies Crowd Out Political Giving? The Missing Link between Charitable and Political Contributions." The B.E. Journal of Economic Analysis \& Policy 15 (1): 407-35. 